\title{
Accuracy of remote diagnoses using intraoral scans captured in approximate true color: a pilot and validation study in teledentistry
}

Sabrina Steinmeier ${ }^{1 *} \mathbb{D}$, Daniel Wiedemeier ${ }^{2} \mathbb{D}$, Christoph H. F. Hämmerle ${ }^{1}(\mathbb{D})$ and Sven Mühlemann ${ }^{1}(\mathbb{D}$

\begin{abstract}
Background: Intraoral scans (IOS) provide three-dimensional images with approximate true colors representing a possible tool in teledentistry for remote examination. The aim of the present cross-sectional validation study was, therefore, to evaluate the levels of agreement between remote diagnoses derived from IOS and diagnoses based on clinical examinations for assessing dental and periodontal conditions.

Methods: The test sample comprised 10 patients representing different clinical conditions. Following the acquisition of IOS (Trios, 3Shape), a full-mouth dental and periodontal examination was done and periapical radiographs were taken. Ten dentists were asked to perform dental and periodontal scorings for each of the ten patients on a tablet computer presenting the IOS. Scores included diagnosis of gingivitis/periodontitis, and evaluated presence as well as amount of plaque and calculus, and presence of teeth exhibiting gingival recession, furcation involvement, erosion, tooth wear, stain, and non-carious cervical lesion, as well as presence of decayed, filled, and crowned teeth and implants. In a second round of assessments, the periapical radiographs were provided and the dentists were able to change the scores. The time for the remote assessment was recorded. The agreement between remote and clinical scorings (reference) was then analyzed descriptively.

Results: The mean time for the tele assessment was $3.17 \mathrm{~min}$ and the additional consultation of the radiographs accounted for another $1.48 \mathrm{~min}$. The sensitivity and specificity values were 0.61 and 0.39 for gingivitis and 0.67 and 0.33 for periodontitis, with no relevant changes when radiographs were provided for the diagnosis of periodontitis (0.72 and 0.28). The agreement for dichotomized dental and periodontal indices ranged between 78 and 95\%. With the provision of radiographs, the remote examiners were able to detect existing filled teeth, crowned teeth, and implants, whereas the detection of decayed teeth (70\%) was not improved.

(Continued on next page)
\end{abstract}

* Correspondence: sabrina.steinmeier@icloud.com

${ }^{1}$ Clinic of Reconstructive Dentistry, Center of Dental Medicine, University of

Zurich, Zurich, Switzerland

Full list of author information is available at the end of the article

(c) The Author(s). 2020 Open Access This article is licensed under a Creative Commons Attribution 4.0 International License, which permits use, sharing, adaptation, distribution and reproduction in any medium or format, as long as you give appropriate credit to the original author(s) and the source, provide a link to the Creative Commons licence, and indicate if changes were made. The images or other third party material in this article are included in the article's Creative Commons licence, unless indicated otherwise in a credit line to the material. If material is not included in the article's Creative Commons licence and your intended use is not permitted by statutory regulation or exceeds the permitted use, you will need to obtain permission directly from the copyright holder. To view a copy of this licence, visit http://creativecommons.org/licenses/by/4.0/ The Creative Commons Public Domain Dedication waiver (http://creativecommons.org/publicdomain/zero/1.0/) applies to the data made available in this article, unless otherwise stated in a credit line to the data. 


\begin{abstract}
(Continued from previous page)
Conclusions: The remote examination using IOS was effective in detecting dental findings, whereas periodontal conditions could not be assessed with the same accuracy. Still, remote assessment of IOS would allow a timeefficient screening and triage of patients. Improvement of the image quality of IOS may further allow to increase the accuracy of remote assessments in dentistry.

According to the Swiss Regulation this investigation is not a clinical trial and therefore no registration in a WHOregistry is needed.
\end{abstract}

Keywords: Teledentistry, Remote diagnosis, Intraoral scan

\section{Background}

Telemedicine is the remote delivery of health care services using information and communication technologies. The broad goal of telemedicine is to improve health of individuals and their communities in underserved areas [1]. Teledentistry is a sub-group of telemedicine and is successfully used within the dental practice for teleconsultation, telediagnosis and delivery of oral care services [2]. When access-to-care is limited (e.g. Covid19 pandemic), teledentistry may allow the continuation of dental health services [3]. A systematic review concluded that teledentistry was a valuable tool for oral screening similar to face-to-face consultations [4]. Several electronic devices were used to capture the intraoral soft and hard tissues such as smartphones, digital extraoral cameras, or intraoral cameras.

Smartphones equipped with imaging technology are readily accessible and very easy to use [5]. A recent study during Covid-19 dissemination showed that patients could be successfully monitored using photos and a messaging service while reducing human contact [6]. In dental traumatology a clinical study showed that the remote diagnosis of dental traumas based on mobile phone pictures was similar to the diagnoses conducted in person [7]. A cross-sectional study showed, that smartphones with photo messaging can serve as an effective tool for the remote screening of potentially malignant oral disorders [8]. Standardized mobile phone pictures were remotely assessed for dental caries without radiographs in children with mixed dentition [9]. Sensitivity and specificity among several dentists were above $80 \%$. A greater reliability was found at primary teeth as compared to permanent teeth. Similarly, a study showed that occlusal caries can be detected with acceptable diagnostic accuracy based on photographs taken by a smartphone camera compared to face-to-face screenings [10]. In orthodontics, the monitoring of linear tooth movements by means of a smartphone software showed an accurate assessment of the real tooth movements [11].

The use of small hand-held intraoral cameras was suggested as a feasible and potentially cost-effective option to a visual oral examination for caries screening in children [12]. A clinical study with a total of 62 children reported that the agreement between digital and conventional clinical examinations was very good for various oral conditions [13]. Sensitivity and specificity were 98.1 and $66.7 \%$ for caries. Similar values were obtained for the detection of stains (99\% sensitivity; $77.8 \%$ specificity), calculus (98\%; 72.7\%), and tooth wear (90.3\%; 81\%). Another study reported that sensitivity and specificity were 73 and $98 \%$ for the remote screening of dental caries in young adults by means of five standardized intraoral photographs [14].

The diagnostic reliability in teledentistry may be limited to the image quality [15], missing clinical data [7], and the two-dimensional representation by photographs [13]. Today, intraoral scanners (IOS) are mainly integrated in the fabrication workflow of chairside reconstructions [16]. These devices can capture the intraoral conditions three-dimensionally and are augmented with close to true colors [17]. Also, IOS resulted in higher patient comfort and less chairside time compared to conventional impression techniques [18].

To the best of our knowledge, no clinical study has evaluated the validity of using intraoral scans with approximate true colors for the screening for diseases affecting the periodontal tissues and dental hard tissues. Evidence that IOS are valid for the screening may change the organizational structure of dental practices leading to a higher adoption and a wider distribution of this technology. Therefore, the aim of this clinical validation study was to assess the agreement between remote screening based on intraoral approximate true color scans and traditional clinical examinations.

\section{Methods}

The study protocol was approved by the Ethical Committee of the University of Zurich, Switzerland, and categorized as a study not being regulated by the law on human research in Switzerland (BASEC-Nr. Req-2019$01277,20.12 .2019$, retrospectively registered). Signed informed consent was obtained from the patients included in this study.

Patients in need of a prosthetic rehabilitation were consecutively screened at the Clinic of Reconstructive Dentistry of the University of Zurich, Switzerland, and 
recruited for the present study. The patients were examined by experienced dentists, who took the intraoral scans and recorded the intraoral findings.

An intraoral scan (Trios, 3Shape, Copenhagen) with approximate true colors was obtained in all patients. The scan included a full-arch scan of both jaws including all teeth and a bite registration of both sides in occlusion. The computed scans were issued with a separate study number to pseudonymize the intraoral scans before being sent to the store-and-forward based server (portal.3shapecommunicate.com).

Detailed dental records were obtained including number and location of teeth, location of caries lesions, of non-carious cervical lesions (NCCL), and of erosive lesions. The location, size, and material of fillings and restorations were also recorded. In addition, tooth mobility [19] and tooth vitality by means of $\mathrm{CO} 2$ testing were assessed. A full-mouth periodontal examination (FMPE) was recorded including probing depth, attachment levels, plaque index [20], bleeding on probing [21], furcation involvement, and gingival recessions. Periapical radiographs were taken when clinically indicated.

The clinical data for each patient were captured in a standardized assessment form and served as control (Table 1). In brief, the amounts of plaque and calculus were rated using a scale with 5 scores, whereas dichotomized scores were applied for the parameters gingival recessions, furcation involvement, tooth erosion, tooth wear, stains and NCCL. The existence of decayed, filled, and crowned teeth as wells as the presence of implants was checked. In addition, the quality of the restorations was evaluated. Gingival and periodontal health were evaluated using a scale with 3 scores (healthy, localized, generalized).

For this validation study, ten patients were selected. The sample of patients was created to represent a wide variety of different clinical situations (Fig. 1). Edentulous patients and patients presenting with Kennedy class 1 were excluded. The overview of the clinical characteristics of the ten patients is presented in Table 1.

The remote examiners, who had a minimum of 3 years of experience as general practitioners, assessed the intraoral scans on a tablet computer (iPad Air, model A1474, Apple Corp. Cupertino, CA) using the software app provided by the manufacturer (3Shape Communicate, Version 4.0.1). The examiners used the standardized assessment form during the tele examination. Thereafter, they were provided with the periapical radiographs and asked to provide a second round of tele assessment. The time for the tele examination was recorded for assessment of the intraoral scans as well as for the additional assessment with the radiographs. The remote scoring (test) was compared to the scoring derived from the clinical data (control).
Each of the 10 patients was scored remotely by 10 examiners resulting in a total of 100 observations per parameter. Data was coded in Microsoft Excel. Analyses and illustrations were generated with the statistical software $\mathrm{R}$ [22], including the package ggplot2 [23]. For the parameters plaque and calculus dentists were grouped according to their years of clinical experience (less than 5 years of clinical experience versus more than 5 years of clinical experience).

\section{Results}

The sample of examiners comprised a total of 10 clinicians (4 females, 6 males) with a mean age of $32.7 \pm 3.5$ years (range 28 to 41 years). None of the examiners has ever done a remote examination by means of approximate true color scans. The mean time ( \pm standard deviation) for the tele screening was $3.17( \pm 1.15)$ minutes and the additional consultation of the radiographs accounted for another $1.48( \pm 0.59)$ minutes.

The agreement for the dichotomized clinical indices (gingival recessions, furcation involvement, tooth erosion, tooth wear, stains and NCCL) ranged between 78 and $95 \%$. The presence or absence of decayed teeth was correctly assessed in 73\% of the cases. This accuracy was higher for filled teeth (98\%), crowned teeth (97\%), and implants (96\%). The provision of the radiographs allowed the remote examiners to correctly detect all filled teeth, crowned teeth, and implants, whereas the detection of decayed teeth (70\%) was not improved. The false negative rate for the detection of decayed teeth was 21 and $23 \%$ with the provision of radiographs. The false positive rate increased from $3 \%$ without radiographs to $23 \%$ with radiographs.

The remote screening of the dentition for the presence or absence of insufficient fillings and crowns was correct in 63 and $65 \%$ of the cases and the provision of radiographs allowed to improve the accuracy for crowns (78\%), but not for fillings (65\%) (Fig. 2). The evaluation of the fillings resulted in $29 \%$ false negatives and in $7 \%$ false positives ( 31 and $4 \%$ with radiographs). The assessment of crown quality revealed $21 \%$ false negatives and $15 \%$ false positives with a decrease when radiographs were consulted $(16 \%$ false negatives and $6 \%$ false positives).

The perfect agreement between the remote assessment and the clinical examination was $35 \%$ for plaque and $40 \%$ for calculus (Fig. 3). The tele consultation resulted in $35 \%$ higher plaque score values (overrating) and in $30 \%$ lower plaque score values (underrating) as compared to the clinical examination. The presence of calculus was overrated in $10 \%$ of the observations, whereas underrating encompassed $51 \%$ of the cases. A moderate agreement represented by a score deviation of \pm 1 unit 
Table 1 Remote scoring form including overview of patient-specific clinical conditions ( $P=$ patient; $n=10$ patients)

\begin{tabular}{|c|c|c|c|c|c|c|c|c|c|c|c|c|}
\hline & Score & Criteria & & & & & & & & & & \\
\hline Clinical indices & & & P1 & $\mathrm{P} 2$ & P3 & P4 & P5 & P6 & P7 & P8 & P9 & P10 \\
\hline \multirow[t]{5}{*}{ Plaque } & 0 & No plaque & & & & & & & & & & \\
\hline & 1 & $\begin{array}{l}\text { Little amounts of plaque (less than 20\% of the tooth } \\
\text { surfaces covered with plaque) }\end{array}$ & $x$ & & $x$ & $x$ & & & & $x$ & & \\
\hline & 2 & $\begin{array}{l}\text { Moderate amounts of plaque (less than } 50 \% \text { of the } \\
\text { tooth surfaces covered with plaque) }\end{array}$ & & & & & & $x$ & & & & $x$ \\
\hline & 3 & $\begin{array}{l}\text { High amounts of plaque (less than } 80 \% \text { of the tooth } \\
\text { surfaces covered with plaque) }\end{array}$ & & & & & $x$ & & $x$ & & $x$ & \\
\hline & 4 & Generalized plaque & & $x$ & & & & & & & & \\
\hline \multirow[t]{5}{*}{ Calculus } & 0 & No calculus & & & & $x$ & & & & & & $x$ \\
\hline & 1 & $\begin{array}{l}\text { Little amounts of calculus (limited to the lingual } \\
\text { surfaces of the lower front teeth) }\end{array}$ & $x$ & & $x$ & & $x$ & $x$ & $x$ & $x$ & & \\
\hline & 2 & $\begin{array}{l}\text { Moderate amounts of calculus (limited to the lingual } \\
\text { surfaces of the lower front teeth and the buccal } \\
\text { surfaces of the maxillary molars) }\end{array}$ & & & & & & & & & & \\
\hline & 3 & $\begin{array}{l}\text { High amounts of calculus (involvement of more tooth } \\
\text { surfaces than the ones of the lower front teeth and the } \\
\text { maxillary molars) }\end{array}$ & & $x$ & & & & & & & $x$ & \\
\hline & 4 & Generalized calculus & & & & & & & & & & \\
\hline \multirow[t]{2}{*}{ Gingival recessions } & 0 & No recessions & & & & $x$ & $x$ & $x$ & & & & \\
\hline & 1 & Presence of recessions & $x$ & $x$ & $x$ & & & & $x$ & $x$ & $x$ & $x$ \\
\hline \multirow[t]{2}{*}{ Furcation involvement } & 0 & No teeth with furcation involvement & & & $x$ & $x$ & $x$ & $x$ & & & & \\
\hline & 1 & Presence of teeth with furcation involvement & $x$ & $x$ & & & & & $x$ & $x$ & $x$ & $x$ \\
\hline \multirow[t]{2}{*}{ Erosions } & 0 & No erosions & $x$ & $x$ & & & & & $x$ & $x$ & $x$ & $x$ \\
\hline & 1 & Presence of erosions & & & $x$ & $x$ & $x$ & $x$ & & & & \\
\hline \multirow[t]{2}{*}{ Tooth wear } & 0 & No signs of tooth wear & & & & & & & & & & \\
\hline & 1 & Presence of tooth wear & $x$ & $x$ & $x$ & $x$ & $x$ & $x$ & $x$ & $x$ & $x$ & $x$ \\
\hline \multirow[t]{2}{*}{ Stains } & 0 & No stains & & & & & $x$ & & & & & \\
\hline & 1 & Presence of stains & $x$ & $x$ & $x$ & $x$ & & $x$ & $x$ & $x$ & $x$ & $x$ \\
\hline \multirow[t]{2}{*}{ Non-carious cervical lesions (NCCL) } & 0 & No NCCL & & & & & $x$ & & & & & $x$ \\
\hline & 1 & Presence of NCCL & $x$ & $x$ & $x$ & $x$ & & $x$ & $x$ & $x$ & $x$ & \\
\hline \multicolumn{13}{|l|}{ Dentition } \\
\hline \multirow[t]{2}{*}{ Decayed teeth } & 0 & No decayed teeth & $x$ & & $x$ & $x$ & $x$ & & & & $x$ & \\
\hline & 1 & Presence of decayed teeth & & $x$ & & & & $x$ & $x$ & $x$ & & $x$ \\
\hline \multirow[t]{4}{*}{ Filled teeth } & 0 & No filled teeth & & & & & & & & & & \\
\hline & 1 & Presence of filled teeth & $x$ & $x$ & $x$ & $x$ & $x$ & $x$ & $x$ & $x$ & $x$ & $x$ \\
\hline & $1 a$ & Sufficient (no intervention needed) & & & & & & & & & & \\
\hline & $1 b$ & At least one filling insufficient (need for intervention) & & & & & & & & & & \\
\hline \multirow[t]{4}{*}{ Crowned teeth } & 0 & No crowned teeth & & $x$ & $x$ & $x$ & $x$ & $x$ & & & & \\
\hline & 1 & Presence of crowned teeth & $x$ & & & & & & $x$ & $x$ & $x$ & $x$ \\
\hline & $1 \mathrm{a}$ & Sufficient (no intervention needed) & & & & & & & & & & \\
\hline & $1 \mathrm{~b}$ & $\begin{array}{l}\text { At least one crowned tooth insufficient } \\
\text { (need for intervention) }\end{array}$ & & & & & & & & & & \\
\hline \multirow[t]{2}{*}{ Implants } & 0 & No implants & & $x$ & $x$ & $x$ & $x$ & $x$ & $x$ & $x$ & $x$ & $x$ \\
\hline & 1 & Presence of implants & $x$ & & & & & & & & & \\
\hline
\end{tabular}

Diagnosis

Gingivitis

$0 \quad$ No gingivitis 
Table 1 Remote scoring form including overview of patient-specific clinical conditions ( $P=$ patient; $n=10$ patients) (Continued)

\begin{tabular}{|c|c|c|c|c|c|c|c|c|c|c|c|c|}
\hline & Score & Criteria & & & & & & & & & & \\
\hline & 1 & Localized gingivitis (less than 30\% of the teeth involved) & $x$ & & $x$ & $x$ & $x$ & $x$ & & & $x$ & $\mathrm{x}$ \\
\hline & 2 & Generalized gingivitis (more than $30 \%$ of teeth involved) & & $x$ & & & & & $x$ & $x$ & & \\
\hline \multirow[t]{3}{*}{ Periodontitis } & 0 & No periodontitis & & & $x$ & $x$ & $x$ & $x$ & & & & \\
\hline & 1 & Localized periodontitis (less than 30\% of the teeth involved) & $x$ & & & & & & $x$ & & $x$ & $\mathrm{x}$ \\
\hline & 2 & Generalized periodontitis (more than $30 \%$ of teeth involved) & & $x$ & & & & & & $\mathrm{x}$ & & \\
\hline
\end{tabular}

was found for $48 \%$ of the plaque scores and $50 \%$ of the calculus scores, whereas a low agreement with score deviations of $\geq 2$ units was limited to $17 \%$ (plaque score) and $11 \%$ (calculus score). The visual representation based on the clinical experience did not reveal a trend (Fig. 3).

The sensitivity and specificity values were 0.61 and 0.39 for gingivitis and 0.67 and 0.33 for periodontitis, with no relevant changes when radiographs were provided for the diagnosis of periodontitis (0.72 and 0.28) (Table 2). The false negative rate for gingivitis and periodontitis was 11 and $3 \%$, respectively. The false positive rate was $28 \%$ for gingivitis and $30 \%$ for periodontitis.

\section{Discussion}

The results of the present study showed that a dentist can make a time-efficient and valid tele screening of the oral soft and hard tissues based solely on approximate true color intraoral scans taken by means of IOS. The agreement between remote diagnosis and clinical diagnosis for dental and periodontal assessments, however, was moderate to low.

The continuous development of hard- and software has made it possible to electronically capture and transmit clinical pictures of patients. The accuracy of teledentistry, however, depends on the selected field of view. Two-dimensional intraoral images have their shortcomings, because they represent a limited two-dimensional

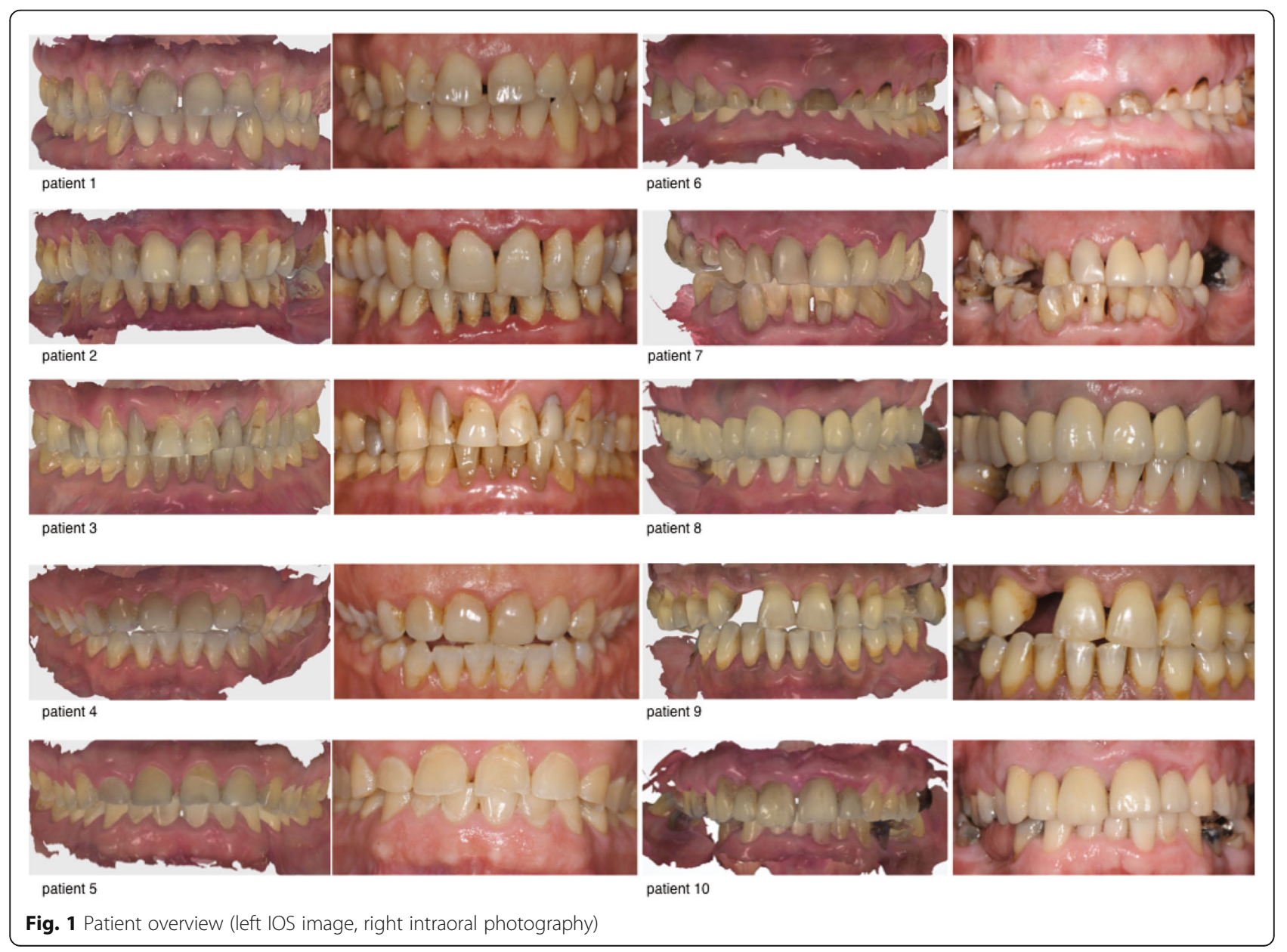




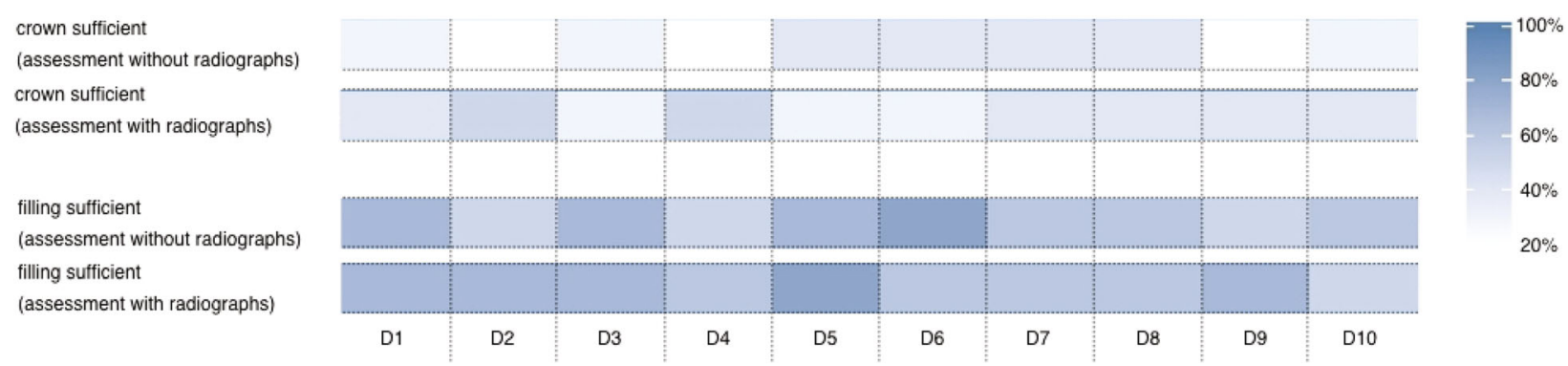

Fig. 2 Heat map for the correct remote assessment of the sufficiency of fillings and crowns (D1 to 10; examining dentist, shades of blue represent the percentage of agreement)

view of three-dimensional soft and hard tissue structures. In a clinical study on the efficacy of remote screening for dental caries, up to $15.4 \%$ of all screened teeth could not be scored because of missing image data [24]). In the present study, all teeth were accessible for the remote screening because intraoral scans provide the full three-dimensional structure of teeth and gingiva. The fact that calculus scores were underrated, however, confirmed that only structures represented on the images can be remotely assessed.

In addition, the quality of the images may influence the outcome of tele evaluations. A clinical study providing smart phone pictures for the remote screening of potentially malignant disorders demonstrated that the false negative rate decreased as the camera resolution increased [15]. The results of the present study showed that the assessment of the remote score for the amount of plaque and calculus was limited. This may be related to the quality of the color images that the software uses for the colorimetric augmentation of the threedimensional file. Anecdotal comments by the remote examiners suggested that the image quality on the tablet software may have been lower than in the IOS software emphasizing that hard- and software may influence the accuracy of remote screening.

The requirements of valid screening tools are time efficiency and accuracy. It was reported that the establishment of a FMPE took a mean of $29 \mathrm{~min}$ [25] and up to $40 \mathrm{~min}$ [26]. Therefore, tests and indexes were established to estimate the prevalence of periodontitis. A systematic review reported sensitivity values of partialmouth examination protocols ranging from 57 to $96 \%$

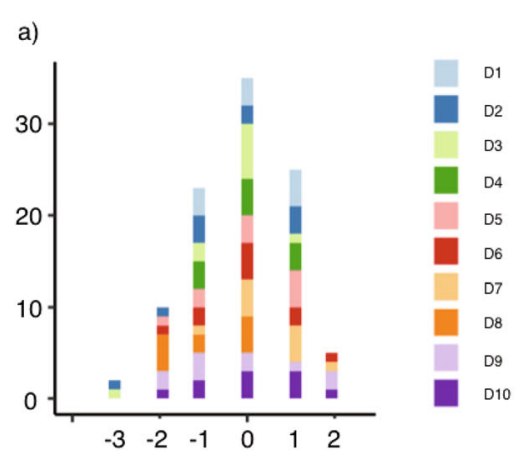

c)

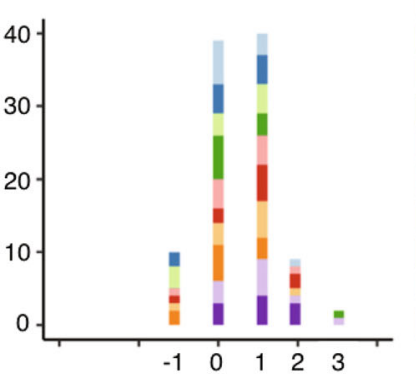

b)

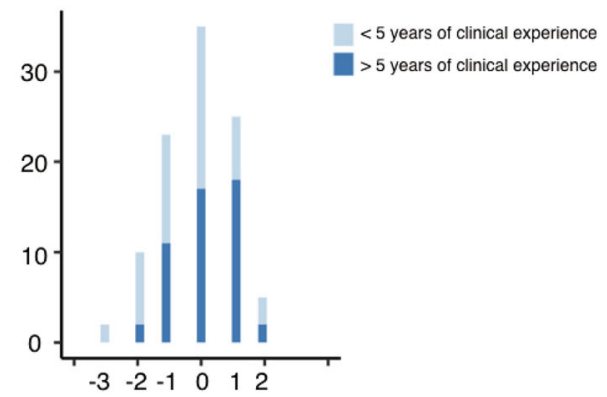

d)

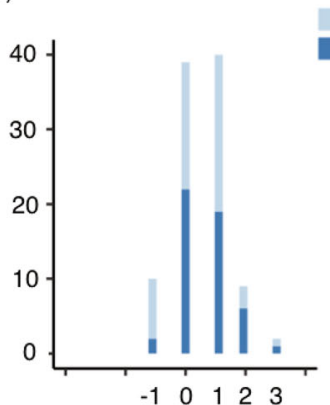

Fig. 3 Difference in scores for the amount of plaque $(\mathbf{a}, \mathbf{b})$ and calculus $(\mathbf{c}, \mathbf{d})$ between remote and clinical assessment: $0=$ perfect agreement, $-/+$ 1 moderate agreement, $-/+2,3$ poor agreement between remote and clinical score. (D, dentist) 
Table 2 Frequency distribution of remote assessments for periodontal conditions (na, not applicable)

\begin{tabular}{|c|c|c|c|c|c|}
\hline \multirow[t]{2}{*}{ Diagnosis } & \multirow[t]{2}{*}{ Clinical reference } & \multicolumn{2}{|c|}{$\begin{array}{l}\text { Remote assessments } \\
(n=100)\end{array}$} & \multicolumn{2}{|c|}{$\begin{array}{l}\text { Remote assessments with radiographs } \\
(n=100)\end{array}$} \\
\hline & & correct & incorrect & correct & incorrect \\
\hline no gingivitis & 0 & 0 & 11 & na & na \\
\hline localized gingivitis & 7 & 41 & 8 & na & na \\
\hline generalized gingivitis & 3 & 20 & 20 & na & na \\
\hline no periodontitis & 4 & 30 & 3 & 35 & 1 \\
\hline localized periodontitis & 4 & 27 & 17 & 22 & 10 \\
\hline generalized periodontitis & 2 & 10 & 13 & 15 & 17 \\
\hline
\end{tabular}

with a higher sensitivity in protocols including the examination of all teeth [27]. The remote assessment of approximate true color scans including the gingival structures resulted in a sensitivity of $67 \%$ for the prevalence of periodontitis. More importantly, the false negative rate for periodontitis was very low (3\%) demonstrating a low risk of missing out patients in need for a periodontal therapy.

A systematic review reported a range for sensitivity values by means of visual inspection for caries detection between 0.35 and 0.78 [28]. In the present study the remote inspection of intraoral scan data revealed a sensitivity of 0.88 for the detection of decayed teeth. The false negative rate for the detection of decayed teeth was high. Therefore, the present method cannot be recommended for caries screening. Recent IOS, however, are equipped with fluorescent or near-infrared light transillumination technology to detect caries lesions concomitant with the acquisition of the three-dimensional images. A clinical study showed the potential of this new technology [29]. Near-infrared light images allowed to detect proximal caries in posterior teeth similar to bitewing radiographs and were superior to the visual inspection alone.

The patient cohort of the present study was selected to represent a wide variety of different clinical situations. The low number of 10 patients, however, is a limitation of this pilot study. Also, comments by the remote examiners suggested that metal restorations were not properly represented on the approximate true color scans demonstrating a limitation of the IOS and its software used in the present study. The continuous development of the IOS will allow to overcome these limitations. Therefore, further clinical studies are needed to validate the diagnostic tools of current IOS.

The recording time as well as the investment costs for an IOS have to be considered. General dental practitioners showed concerns in relation to excessive time spent in capturing images and transmission of information [30]. The dental practices' organizational structure, however, may be adapted by delegating image acquisition to dental auxiliary staff. Today, IOS are primarily used for the fabrication of reconstructions and dental appliances. The potential advantages associated with the use of IOS for remote screening of early diagnosis and the need for treatments may justify the high investment costs.

\section{Conclusions}

The remote examination using IOS was effective in detecting dental findings, whereas periodontal conditions could not be assessed with the same accuracy. The use of a periodontal probe during clinical examination could not be compensated by IOS only. Still, remote assessment of IOS would allow a time-efficient screening and triage of patients.

\section{Abbreviations}

IOS: Intraoral scans; e.g.: For example; FMPE: Full-mouth periodontal examination; NCCL: Non-carious cervical lesions

\section{Acknowledgements \\ Sabrina Steinmeier sabrina.steinmeier@icloud.com \\ ORCID 0000-0003-2832-0025. \\ Daniel Wiedemeier daniel.wiedemeier@zzm.uzh.ch \\ ORCID 0000-0001-8997-700X. \\ Christoph Hämmerle christoph.hammerle@zzm.uzh.ch \\ ORCID 0000-002-8280-7347. \\ Sven Mühlemann sven.muehlemann@zzm.uzh.ch \\ ORCID 0000-0003-1253-1813.}

Authors' contributions

S.S., D.W., S.M. conceived the ideas; S.S. collected the data; S.S., D.W., S.M. analyzed the data; and S.S., D.W., C.H., S.M. performed the writing. The author(s) read and approved the final manuscript.

\section{Funding}

The authors did not receive any financial support.

\section{Availability of data and materials}

The datasets used and analysed during the current study are available from the corresponding author on reasonable request.

\section{Ethics approval and consent to participate}

According to the Swiss Regulation this investigation is not a clinical trial and therefore no registration in a WHO-registry is needed. Signed informed consent was obtained from the patients included in this study.

Consent for publication

Not applicable.

Competing interests

The authors declare that they have no competing interests. 


\section{Author details}

Clinic of Reconstructive Dentistry, Center of Dental Medicine, University of Zurich, Zurich, Switzerland. ${ }^{2}$ Statistical Services, Center of Dental Medicine, University of Zurich, Zurich, Switzerland.

\section{Received: 5 August 2020 Accepted: 20 September 2020}

Published online: 25 September 2020

\section{References}

1. WHO GCoHT: A health telematics policy in support of WHO's health-for-all strategy for global health development: report of the WHO Group consultation on health telematics. 1998.

2. Khan SA, Omar H. Teledentistry in practice: literature review. Telemed J E Health. 2013;19(7):565-7.

3. Talla PK, Levin L, Glogauer M, Cable C, Allison PJ. Delivering dental care as we emerge from the initial phase of the COVID-19 pandemic: teledentistry and face-to-face consultations in a new clinical world. Quintessence Int. 2020;51(8):672-7.

4. Alabdullah $J \mathrm{H}$, Daniel SJ. A systematic review on the validity of Teledentistry. Telemed J E Health. 2018;24(8):639-48.

5. Daniel SJ, Kumar S. Teledentistry: a key component in access to care. J Evid Based Dent Pract. 2014;14(Suppl):201-8.

6. Giudice A, Barone S, Muraca D, Averta F, Diodati F, Antonelli A, Fortunato L. Can teledentistry improve the monitoring of patients during the covid-19 dissemination? a descriptive pilot study. Int J Environ Res Public Health. 2020:17(10):3399 1-9.

7. de Almeida GR, Rezende L, da Silva CQ, Almeida JCF. Remote diagnosis of traumatic dental injuries using digital photographs captured via a mobile phone. Dent Traumatol. 2017;33(5):350-7.

8. Vinayagamoorthy K, Acharya S, Kumar M, Pentapati KC, Acharya S. Efficacy of a remote screening model for oral potentially malignant disorders using a free messaging application: a diagnostic test for accuracy study. Aust J Rural Health. 2019;27(2):170-6.

9. AlShaya MS, Assery MK, Pani SC. Reliability of mobile phone teledentistry in dental diagnosis and treatment planning in mixed dentition. J Telemed Telecare. 2020;26(1-2):45-52.

10. Estai M, Kanagasingam Y, Huang B, Shiikha J, Kruger E, Bunt S, Tennant M. Comparison of a smartphone-based photographic method with face-to-face caries assessment: a Mobile Teledentistry model. Telemed J E Health. 2017; 23(5):435-40.

11. Moylan HB, Carrico CK, Lindauer SJ, Tufekci E. Accuracy of a smartphonebased orthodontic treatment-monitoring application: a pilot study. Angle Orthod. 2019;89(5):727-33.

12. Kopycka-Kedzierawski DT, Billings RJ, McConnochie KM. Dental screening of preschool children using teledentistry: a feasibility study. Pediatr Dent. 2007; 29(3):209-13.

13. Pentapati KC, Mishra P, Damania M, Narayanan S, Sachdeva G, Bhalla G. Reliability of intra-oral camera using teledentistry in screening of oral diseases - pilot study. Saudi Dent J. 2017;29(2):74-7.

14. Morosini Ide A, de Oliveira DC, Ferreira Fde M, Fraiz FC, Torres-Pereira CC. Performance of distant diagnosis of dental caries by teledentistry in juvenile offenders. Telemed J E Health. 2014;20(6):584-9.

15. Haron N, Zain RB, Nabillah WM, Saleh A, Kallarakkal TG, Ramanathan A, Sinon SH, Razak IA, Cheong SC. Mobile phone imaging in low resource settings for early detection of Oral Cancer and concordance with clinical Oral examination. Telemed J E Health. 2017;23(3):192-9.

16. Muhlemann S, Sandrini G, loannidis A, Jung RE, Hammerle CHF. The use of digital technologies in dental practices in Switzerland: a cross-sectional survey. Swiss Dent J. 2019;129(9):700-7.

17. Mangano F, Gandolfi A, Luongo G, Logozzo S. Intraoral scanners in dentistry: a review of the current literature. BMC Oral Health. 2017;17(1):149.

18. Yuzbasioglu E, Kurt H, Turunc R, Bilir H. Comparison of digital and conventional impression techniques: evaluation of patients' perception, treatment comfort, effectiveness and clinical outcomes. BMC Oral Health. 2014;14:10.

19. Flemming T: Parodontolgie. Ein Kompendium. Georg Thieme Verlag 1993(ISBN-13: 978-3-13-799401-5).

20. Silness J, Loe H. Periodontal disease in pregnancy. li. Correlation between Oral hygiene and periodontal Condtion. Acta Odontol Scand. 1964;22:12135 .
21. Ainamo J, Bay I. Periodontal indexes for and in practice. Tandlaegebladet. 1976:80(5):149-52

22. R Core Team. R: A language and environment for statistical computing. Vienna, Austria. URL https://www.R-project.org/: R Foundation for Statistical Computing; 2018.

23. Wickham H. Elegant graphics for data analysis. New York: Springer-Verlag; 2016

24. Estai M, Kanagasingam $Y$, Huang B, Checker H, Steele L, Kruger E, Tennant $M$. The efficacy of remote screening for dental caries by mid-level dental providers using a mobile teledentistry model. Community Dent Oral Epidemiol. 2016:44(5):435-41.

25. Owens JD, Dowsett SA, Eckert GJ, Zero DT, Kowolik MJ. Partial-mouth assessment of periodontal disease in an adult population of the United States. J Periodontol. 2003;74(8):1206-13.

26. Benigeri M, Brodeur JM, Payette M, Charbonneau A, Ismail Al. Community periodontal index of treatment needs and prevalence of periodontal conditions. J Clin Periodontol. 2000;27(5):308-12.

27. Tran DT, Gay I, Du XL, Fu Y, Bebermeyer RD, Neumann AS, Streckfus C, Chan W, Walji MF. Assessing periodontitis in populations: a systematic review of the validity of partial-mouth examination protocols. J Clin Periodontol. 2013; 40(12):1064-71.

28. Gimenez T, Piovesan C, Braga MM, Raggio DP, Deery C, Ricketts DN, Ekstrand KR, Mendes FM. Visual inspection for caries detection: a systematic review and meta-analysis. J Dent Res. 2015:94(7):895-904.

29. Kunisch J, Schaefer G, Pitchika V, Garcia-Godoy F, Hickel R. Evaluation of detecting proximal caries in posterior teeth via visual inspection, digital bitewing radiography and near-infrared light transillumination. Am J Dent. 2019;32(2):74-80.

30. Stephens C, Cook J, Mullings C. Orthodontic referrals via TeleDent southwest. Dent Clin N Am. 2002;46(3):507-20.

\section{Publisher's Note}

Springer Nature remains neutral with regard to jurisdictional claims in published maps and institutional affiliations.

Ready to submit your research? Choose BMC and benefit from:

- fast, convenient online submission

- thorough peer review by experienced researchers in your field

- rapid publication on acceptance

- support for research data, including large and complex data types

- gold Open Access which fosters wider collaboration and increased citations

- maximum visibility for your research: over $100 \mathrm{M}$ website views per year

At BMC, research is always in progress.

Learn more biomedcentral.com/submissions 